\title{
Primary Hydatid Cyst of the Thyroid Gland Revealed by Primary Hypothyroidism
}

\section{Salem Bouomrani1,2*, Oussema Souissi1 ${ }^{1}$, Nesrine Regaieg1,2 and} Mayeda BenHamed 1,2

${ }^{1}$ Department of Internal Medicine, Military Hospital of Gabes, Tunisia

${ }^{2}$ Sfax Faculty of Medicine, University of Sfax, Tunisia

*Corresponding author: Salem Bouomrani, Department of Internal medicine, Military Hospital of Gabes, Tunisia, Tel: +00216 9897755; Email: salembouomrani@yahoo.fr

\section{Case Report}

Received Date: December 06, 2018

Published Date: December 17, 2018
Volume 2 Issue 3

\section{Abstract}

Introduction: The thyroid localization of the hydatid cyst (HC) remains exceptional and unusual even in countries where this Parasitosis is still endemic: its frequency varies from 0.1 to $0.6 \%$ depending on the series. It is most often asymptomatic or resulting in anterior cervical swelling or more rarely a hoarseness of the voice. We report an original observation of thyroid HC revealed by primary hypothyroidism.

Observation: An eight-year-old patient with no notable pathological history was explored for normochromic normocytic anemia at $8 \mathrm{~g} / \mathrm{dl}$. The clinical examination found neither jaundice nor splenomegaly. There was anterior cervical swelling that was painless and lateralized to the right. No lymphadenopathy or other palpable mass was noted. Biology revealed peripheral hypothyroidism with TSH at $7.83 \mu \mathrm{IU} / \mathrm{ml}$. The balance of hereditary hemolytic anemias was negative. Cervical ultrasonography and CT showed an anechoic anterior cervical mass $2.51 \mathrm{~cm}$ in diameter, occupying the right thyroid lobe, without micro calcifications, intracystic vegetation, or adenopathies. Hydatid serodiagnostic was positive. The diagnosis of thyroid HC was confirmed by histological examination post loboishmectomy. The total blood count and TSH were spontaneously corrected after one month of the surgery.

Conclusion: The diagnosis of HC is worthy of mention in the presence of peripheral hypothyroidism with increased thyroid gland volume, especially in endemic areas. This location can sometimes hide associated thyroid neoplasia.

Keywords: Hydatid Cyst; Primary Hypothyroidism; Thyroid Gland; Echinococcosis; Parasitosis

\section{Abbreviations: HC: Hydatid Cyst.}

\section{Introduction}

Echinococcosis is a zoonosis that continues to be a major public health problem in many parts of the world where it is still endemic [1-5]. All organs and/or tissues may be the site of single or multiple hydatid cyst (Kc) $[6,7]$. The most frequent locations of human hydatid disease are the liver (65-70\% of cases) and the lungs (25\% of cases) [2,4]. The extra-pulmonary and extrahepatic sites are exceptional and little known. They are therefore described as atypical or unusual by most authors [6-8], or even "ectopic" and "aberrant" by some [9]. 
Because of their scarcity and the lack of knowledge by most medical practitioners, these unusual, but sometimes potentially fatal [10], localizations of human Echinococcosis, often represent a real diagnostic and therapeutic challenge, especially since clinical presentations are not stereotyped [6,11].

We are reporting an original case of $\mathrm{HC}$ of the thyroid gland revealed by primary hypothyroidism, a clinical presentation that, to our knowledge, has not been reported previously.

\section{Case Report}

An eight-year-old patient with no notable pathological history was hospitalized for exploration of normochromic normocytic anemia at $8 \mathrm{~g} / \mathrm{dl}$, found on a systemic checkup. The clinical examination found neither jaundice nor splenomegaly. We noted a cervical swelling anterior, renitent, painless, and lateralized on the right. It was not noted neither lymphadenopathy nor other palpable mass. The biology revealed primary hypothyroidism with a TSH at $7.83 \mu \mathrm{IU} / \mathrm{ml}$ and free thyroxin (fT4) at $3 \mathrm{pmol} / \mathrm{l}$. The balance of hereditary hemolytic anemias was negative. The cervical ultrasound showed a uni-vesicular and anechoic mass of $2.51 \mathrm{~cm}$ in diameter, at the expense of the right thyroid lobe, and repressing the rest of the thyroid parenchyma (Figure 1). The cervical tom densitometry showed a cystic mass, well limited, $2.5 \mathrm{~cm}$ in diameter, and not enhancing after injection of contrast, occupying the entire right lobe of the thyroid and pushing back the parenchyma which reduced to a thin tissue blade (Figures 2a \& 2b). Adenomegalies, micro calcifications, and intra-cystic vegetations have not been reported (Figure 3).

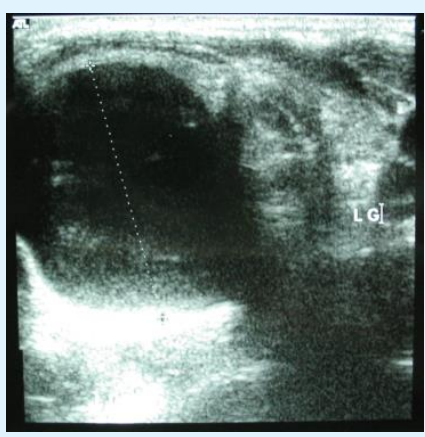

Figure 1: Cervical ultrasound: Uni-vesicular and anechoic mass of $25 \mathrm{~mm}$ in diameter at the expense of the right thyroid lobe.
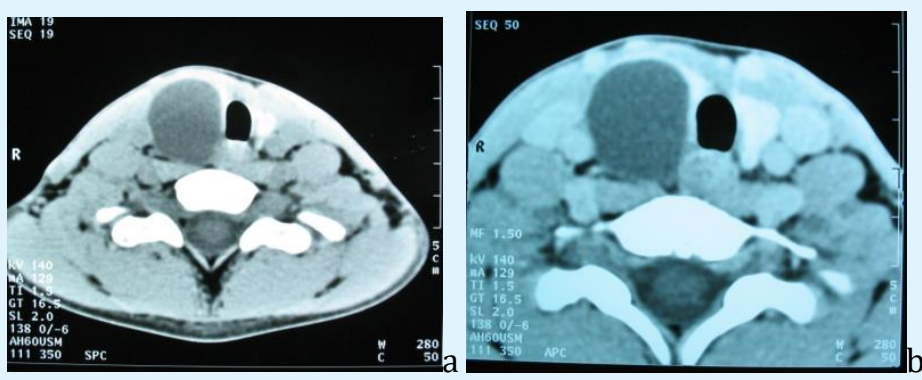

Figure 2: Cervical CT in axial section without (a) and with (b) injection of contrast: well limited, and non-enhanced cystic mass at the expense of the right lobe of the thyroid.

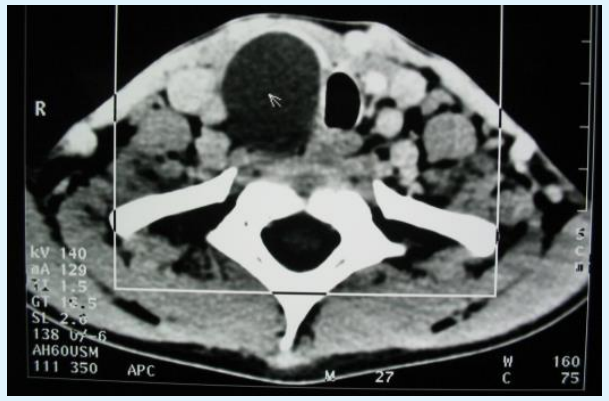

Figure 3: Cervical CT in axial section without injection of contrast: voluminous cystic thyroid mass, without microcalcifications, or intracystic vegetations or adenopathies, with disappearance of the thyroid parenchyma. 


\section{Journal of Infectious Diseases \& Travel Medicine}

For its hypothyroidism, the specific immunological assessment was negative (anti-thyroglobulin and antiThyroperoxidase antibodies) as well as the screening for autoimmune or systemic diseases that may be the cause, particularly systemic lupus erythematous, nephropathy or nephrotic syndrome. The hydatid serology was positive.

Radiological investigations (chest X-ray, abdominal ultrasound, and abdominopelvic CT) did not show other cystic locations. Thus, the diagnosis of a primitive and isolated $\mathrm{HC}$ of the thyroid gland was retained.

The patient was operated (right lobo-ishmectomy) without incident. The diagnosis of thyroid $\mathrm{HC}$ was confirmed by histological examination of the operative specimen. The blood count and TSH were spontaneously corrected after one month of the surgery. The current follow-up is six years.

\section{Discussion}

The primitive forms of these unusual localizations of human Echinococcosis (isolated, without associated hepatic or pulmonary involvement) are exceptional: only $0.9 \%$ in the series of Lianos GD et al collected over 33 years of experience [11].

The thyroid localization of HC remains unusual, even in the series of highly endemic countries for this Parasitosis; in fact, no case of HC of the thyroid gland was found in the Tunisian series of Bellil S, et al. [3] of 265 operated extra pulmonary $\mathrm{HC}$, in the Iranian series of Vahedi MA et al of 318 patients operated for HC [5], in the Turkish series of Gun E [6] of 329 cases of HC collected over 10 years with 72 cases of unusual localizations, and in the Greek series of Lianos GD et al of 233 cases of HC with 18 Unusual locations [11]. Only one case of thyroid $\mathrm{HC}$ was noted in the Akcam AT, et al. [12]. Turkish series of 661 operated HC including 134 of unusual localization $(0.15 \%)$ and a single case was also noted in Çakir M, et al. [8] series of $157 \mathrm{HC}$ of unusual localization (0.6\%). The few other observations found in the literature were reported as sporadic cases [13-21].

The overall frequency of primary thyroid Echinococcosis is thus estimated at 0.1 and $0.6 \%$ [22]. Clinically, it may manifest as basal-cervical, anterior, soft or firm swelling, isolated without associated pain syndrome, compressive sign, or loco regional extension. These characteristics generally lead to benignity without being specific of HC [13-20].
No case of thyroid hormone deficiency associated with this location has been found in the literature. In our observation, revealing hypothyroidism could be explained by the compression of the thyroid parenchyma by the voluminous cyst causing suffering of thyroid cells. The negativity of anti-thyroid autoantibodies, the normality of the histological examination of the residual thyroid parenchyma, the absence of associated systemic diseases, as well as the normalization of thyroid tests after surgical excision of the hydatid cyst, favored this hypothesis. The biological assessment in the case of thyroid HC may show a moderately high eosinophilia or sedimentation rate, and hydatid serology is not always positive [13-20].

Radio graphically, an ultrasound is always required to characterize the nature of the cyst. It most frequently shows a cystic mass with a thin wall, sometimes with detached membrane (water-lily-sign) or the presence of daughter cysts (rosette-like or honeycomb cyst). These aspects (water-lily-sign, rosette-like or honeycomb cyst) are suggestive of the hydatic origin [13-21]. However, the sensitivity of ultrasound remains low. In addition, peripheral arciform calcifications, although strongly suggestive of the diagnosis, are not specific. Computed tomography makes it possible to better specify the seat of the cyst and its relationship with neighboring organs [1320].

Punctures of hydatid cysts have long been proscribed because of the theoretical risk of swarming and anaphylactic shock [21], but cytology by aspiration of cyst contents, looking for scolex is very specific when it is positive. The search for other localizations in a patient with thyroid HC is systematic (thoracic radiography, abdominal ultrasonography, and abdominopelvic CT) to distinguish primary forms from secondary ones and to guide the therapeutic management [15-21].

Treatment of thyroid $\mathrm{HC}$ is essentially surgical, consisting of excision of cysts to prevent complications such as: choking, vocal cord paralysis, intra tracheal rupture, suppuration or intra cystic haemorrhage [13-22]. Three main options are possible: simple resection and partial or total pericystectomy. Medical treatment by Albendazole is proposed for unresectable HC [13-22]. The prognosis is usually favorable; however, an anecdotal case of thyroid cancer concomitant to $\mathrm{HC}$ of the thyroid gland was reported [13].

\section{Conclusion}

The thyroid localization of HC remains exceptional and not usual during this Parasitosis, even in endemic 
countries. This diagnosis deserved to be known and evoked in front of any anterior cervical tumefaction in endemic area for Echinococcosis. Our observation is distinguished by its mode of revelation (primary hypothyroidism by compression of the thyroid parenchyma) which, to our knowledge, has not been reported previously.

\section{Conflicts of Interest: None}

\section{References}

1. McManus DP, Thompson RC (2003) Molecular epidemiology of cystic Echinococcosis. Parasitology 127: 37-51.

2. Grosso G, Gruttadauria S, Biondi A, Marventano S, Mistretta A (2012) Worldwide epidemiology of liver hydatidosis including the Mediterranean area. World J of Gastroentero 18(13): 1425-1437.

3. Bellil S, Limaiem F, Bellil K, Chelly I, Mekni A, et al. (2009) Descriptive epidemiology of extra pulmonary hydatid cysts: a report of 265 Tunisian cases. Tunis Med 87(2): 123-126.

4. Moro P, Schantz PM (2009) Echinococcosis a review. International Journal of Infectious Diseases 13(2): 125-133.

5. Vahedi MA, Vahedi ML (2012) Demographics of patients with surgical and nonsurgical cystic Echinococcosis in East Azerbaijan from 2001 to 2012. Pak J Biol Sci 15(4): 186-191.

6. Gun E, Etit D, Buyuktalanci DO, Cakalagaoglu F (2017) Unusual locations of hydatid disease: A 10-year experience from a tertiary reference center in Western Turkey. Ann Diagn Pathol 29: 37-40.

7. Keser SH, Selek A, Ece D, Barişik CC, Şensu S, et al. (2017) Review of Hydatid Cyst with Focus on Cases with Unusual Locations. Turk Patoloji Derg 33(1): 3036.

8. Çakır M, Balasar M, Küçükkartallar T, Tekin A, Kartal A, et al. (2016) Management of ExtraHepatopulmonary Hydatid Cysts (157 cases). Turkiye Parazitol Derg 40(2): 72-76.

9. Saadi A, Bouzouita A, Cherif M, Rebai MH, Kerkeni W, Ayed H, et al. (2015) Retrovesical hydatic cyst: About 4 cases. Can Urol Assoc J 9(5-6): 374-378.
10. Salamone G, Licari L, Randisi B, Falco N, Tutino R, et al. (2016) Uncommon localizations of hydatid cyst. Review of the literature. G Chir 37(4): 180-185.

11. Lianos GD, Lazaros A, Vlachos K, Georgiou GK, Harissis HV, et al. (2015) Unusual locations of hydatid disease: a 33 years' experience analysis on 233 patients. Updates Surg 67(3): 279-282.

12. Akcam AT, Ulku A, Koltas IS, Izol V, Bicer OS, et al. (2014) Clinical characterization of unusual cystic echinococcosis in southern part of Turkey. Ann Saudi Med 34(6): 508-516.

13. Akbulut S, Demircan F, Sogutcu N (2015) Hydatid cyst disease of the thyroid gland: report of two cases. Int Surg 100(4): 643-647.

14. Yilmaz M, Akbulut S, Sogutlu G, Arabaci E, Kayaalp C (2013) Hydatid cyst of the thyroid gland: report of three cases. Surg Today 43(8): 937-941.

15. Capoğlu I, Unüvar N, Erdogan F, Yilmaz O, Caydere M (2002) A hydatid cyst of the thyroid gland. J Int Med Res 30(2): 206-209.

16. Moghimi M, Kamrava SK, Asghari AM, Behzadi AH, Jalessi M, et al. (2009) Primary echinococcal cyst in the thyroid gland: a case report from Iran. J Infect Dev Ctries 3(9): 732-734.

17. Van Rensburg PS, Joubert IS, Nel CJ (1990) Primary echinococcus cyst of the thyroid. A case report. S Afr J Surg 28(4): 157-158.

18. Kocaoglu H (1961) Hydatid cyst of the thyroid body. J Chir (Paris) 81: 383-386.

19. Pérez P JA, Felmer E O, Carrasco E C, Gabrielli N M, Torrijos C C, et al. (2008) Thyroid hydatid cyst: report of one case. Rev Med Chil 136(7): 896-899.

20. Yuksel M, Demirpolat G, Sever A, Bakaris S, Bulbuloglu E, et al. (2007) Hydatid disease involving some rare locations in the body: a pictorial essay. Korean J Radiol 8(6): 531-540.

21. Dissanayake PI, Chennuri R, Tarjan G. (2016) Fineneedle aspiration diagnosis of primary hydatid disease of the thyroid; first reported case in the USA. Diagn Cytopathol 44(4): 334-347.

Lada P, Lermite E, Hennekinne-Mucci S, Etienne S, Pessaux P, et al. (2005) Primary hydatid cyst of the thyroid, an unusual localisation of hydatidosis. Presse Med 34(8): 580. 